\title{
How effective is retrieval support for witnesses with different levels of working and source memory?
}

Citation for published version (APA):

Krix, A. C., Sauerland, M., Merckelbach, H., Gabbert, F., \& Hope, L. (2015). How effective is retrieval support for witnesses with different levels of working and source memory? Journal of Cognitive Psychology, 27(3), 335-348. https://doi.org/10.1080/20445911.2014.1003219

Document status and date:

Published: 03/04/2015

DOI:

10.1080/20445911.2014.1003219

Document Version:

Publisher's PDF, also known as Version of record

Document license:

Taverne

Please check the document version of this publication:

- A submitted manuscript is the version of the article upon submission and before peer-review. There can be important differences between the submitted version and the official published version of record.

People interested in the research are advised to contact the author for the final version of the publication, or visit the DOI to the publisher's website.

- The final author version and the galley proof are versions of the publication after peer review.

- The final published version features the final layout of the paper including the volume, issue and page numbers.

Link to publication

\footnotetext{
General rights Owners
rights.

- You may freely distribute the URL identifying the publication in the public portal. please follow below link for the End User Agreement:

www.umlib.nl/taverne-license

Take down policy

If you believe that this document breaches copyright please contact us at:

repository@maastrichtuniversity.nl

providing details and we will investigate your claim.
}

Copyright and moral rights for the publications made accessible in the public portal are retained by the authors and/or other copyright owners and it is a condition of accessing publications that users recognise and abide by the legal requirements associated with these

- Users may download and print one copy of any publication from the public portal for the purpose of private study or research.

- You may not further distribute the material or use it for any profit-making activity or commercial gain

If the publication is distributed under the terms of Article $25 \mathrm{fa}$ of the Dutch Copyright Act, indicated by the "Taverne" license above, 


\section{How effective is retrieval support for witnesses with different levels of working and source memory?}

\section{Alana C. Krix, Melanie Sauerland, Harald Merckelbach, Fiona Gabbert \& Lorraine Hope}

To cite this article: Alana C. Krix, Melanie Sauerland, Harald Merckelbach, Fiona Gabbert \& Lorraine Hope (2015) How effective is retrieval support for witnesses with different levels of working and source memory?, Journal of Cognitive Psychology, 27:3, 335-348, DOI:

10.1080/20445911.2014.1003219

To link to this article: https://doi.org/10.1080/20445911.2014.1003219

\section{Published online: 27 Jan 2015.}

Submit your article to this journal 줄

III Article views: 489

Q View related articles $\sqsubset$

View Crossmark data $[\pi$

Citing articles: 1 View citing articles \ulcorner 


\title{
How effective is retrieval support for witnesses with different levels of working and source memory?
}

\author{
Alana C. Krix ${ }^{1}$, Melanie Sauerland ${ }^{1}$, Harald Merckelbach ${ }^{1}$, Fiona Gabbert ${ }^{2}$, and \\ Lorraine Hope ${ }^{3}$
}

${ }^{1}$ Faculty of Psychology and Neuroscience, Forensic Psychology Section, Maastricht

University, P.O. Box 616, 6200 MD Maastricht, The Netherlands

${ }^{2}$ Department of Psychology, Goldsmiths University of London, New Cross, London SE14 $6 \mathrm{NW}, \mathrm{UK}$

${ }^{3}$ Department of Psychology, University of Portsmouth, King Henry I Street, Portsmouth, Hampshire PO1 2DY, UK

(Received 19 December 2013; accepted 23 December 2014)

\begin{abstract}
The present study examined the effectiveness of retrieval support for witnesses who differ in working memory capacity (WMC) and source monitoring abilities. We hypothesised that the provision of retrieval support, relative to free recall, would compensate deficits linked to lower working memory and source monitoring abilities by providing more structure and context cues for retrieval. Thus, we expected no associations between recall performance and WMC and source monitoring abilities in the retrieval support group, but significant positive associations in the free recall group. This study combined data from two experiments $(N=$ $125)$ in which participants either received retrieval support with the Self-Administered Interview or completed a free recall along with working and source memory tests. Contrary to our expectations, presence of retrieval support did not moderate the relationship between WMC and recall performance. In one of two source memory tests, higher source memory scores were associated with more accurate accounts in the retrieval support group, whereas in the free recall group, lower source memory scores were associated with higher recall accuracy. This suggests that individuals with lower source memory abilities may not benefit from retrieval support. We encourage replication with a more heterogeneous sample.
\end{abstract}

Keywords: Eyewitness memory; Retrieval support; Self-Administered Interview; Source monitoring; Working memory capacity.

Eyewitnesses are of crucial importance to the police and the courts, but their accounts can be incomplete or, even worse, inaccurate. There are many factors that influence the completeness and accuracy of eyewitness statements. These not only include situational factors, such as distance or lighting

Correspondence should be addressed to Alana C. Krix, Faculty of Psychology and Neuroscience, Forensic Psychology Section, Maastricht University, P.O. Box 616, 6200 MD Maastricht, The Netherlands. E-mail: Alana.Krix@maastrichtuniversity.nl

We thank Jessica Arnet, Nils Hagemann, Annick Janssen, Stéphanie Kerkhofs, Brenda Nuñez-Gonzalez, Chiel Slegers, Tamara Sujew and Brenda Urban for their help with data collection and Maarten Peters for his valuable comments on an earlier version of the manuscript. We are also grateful to Timm M. Kuhl for preparing the data for analysis.

No potential conflict of interest was reported by the authors.

This research was supported by a PhD scholarship from Studienstiftung des deutschen Volkes (German National Academic Foundation) awarded to the first author. 
conditions, but also cognitive factors (Wells, 1978). In the current paper, we focus on two cognitive factors that are especially relevant for successful retrieval, namely working memory and source monitoring.

During retrieval from long-term memory, working memory is involved in maintenance and manipulation of information (e.g., Baddeley, 2000). In Baddeley's (Baddeley, 2010; Baddeley \& Hitch, 1974) classic model, working memory comprises multiple short-term memory stores for verbal and visuo-spatial material. The model also includes the central executive that is responsible for attentional control and the supervision of the short-term memory stores. Similarly, Engle and colleagues (Engle \& Kane, 2004; Engle, Tuholski, Laughlin, \& Conway, 1999) conceptualise working memory as consisting of domain-specific memory caches with rehearsal processes and domain-general executive attention. Individual differences in working memory capacity (WMC) are considered to reflect differences in executive attention. In Engle and colleagues' (Engle et al., 1999; Engle \& Kane, 2004) model, executive attention is important for accessing information in long-term memory traces and holding this information together with current task goals active, especially during the simultaneous completion of complex tasks. Executive attention is also considered important for resolving interference through cognitive inhibition (i.e., attending to relevant information and suppressing irrelevant information) during retrieval and monitoring of previous recall output (Baddeley, Emslie, Kolodny, \& Duncan, 1998; Jahanshahi, Saleem, Ho, Dirnberger, \& Fuller, 2006). To date, there is no consensus as to whether WMC is part of, or independent to, executive functioning. Whereas working memory is sometimes subsumed under executive functioning (e.g., Elliott, 2003), other researchers consider it to be independent, yet closely related to executive functioning (McCabe, Roediger, McDaniel, Balota, \& Hambrick, 2010). Research has found both working memory and executive functioning to be highly correlated and to share the underlying component of executive attention (McCabe et al., 2010). Indeed, WMC is correlated with performance in executive attention tasks, such as the Stroop task, as well as with higher level cognition, such as fluid intelligence (Kane \& Engle, 2002). Moreover, both WMC and executive functioning are associated with prefrontal cortex activity (Kane \& Engle, 2002). To summarise, successful retrieval is affected by WMC via the underlying executive attention component that is responsible for accessing and maintaining information from long-term memory, as well as for monitoring previous recall output (Engle \& Kane, 2004; Jahanshahi et al., 2006).

Another important aspect for successful retrieval is source monitoring (Johnson, Hashtroudi, \& Lindsay, 1993). Source monitoring occurs during working memory tasks and, like working memory, is intimately linked to prefrontal activity (Mitchell, Johnson, Raye, \& Greene, 2004). Source monitoring refers to evaluations of the origins of memory material (e.g., does a remembered detail originate from the witnessed incident or from a different occasion?). Source monitoring evaluations are thought to rely on characteristics of the memory material, such as perceptual (e.g., sounds) and affective details, as well as the cognitive operations that are involved (e.g., deductions). Thus, material that stems from experienced events is thought to contain more perceptual, contextual and affective information and fewer cognitive operations than material that originates from imagination or fantasy. Errors in source monitoring can occur for several reasons (Johnson et al., 1993; see also the Constructive Memory Framework; Schacter, Norman, \& Koutstaal, 1998). Since source monitoring entails the evaluation of activated memory records, it is dependent on the quality of the encoded information, including the binding of the different features of an event to form a coherent representation. Source monitoring is also dependent on the quality of the retrieved information. Here working memory comes into play, which is responsible for accessing and holding active information from long-term memory. Finally, source monitoring relies on the quality of the judgement processes (e.g., use of appropriate criteria for the source decision). To summarise, source monitoring affects successful retrieval by determining the origin of the retrieved memory material. For this purpose, the characteristics of the memory material are evaluated. The quality of this evaluation depends on the quality of the encoded and retrieved information, as well as on the quality of the employed judgement processes (Johnson et al., 1993).

WMC and source monitoring can influence both correct recall and recall errors (e.g., McCabe et al., 2010; Unsworth \& Brewer, 2010b; Unsworth \& Engle, 2007; Zhu et al., 2010). Individuals with lower WMC typically recall fewer correct items than individuals with higher WMC (e.g., Rosen \& Engle, 1997; Unsworth \& Brewer, 2010b). Moreover, low WMC and deficits in source monitoring are associated with more recall errors (e.g., Unsworth \& Brewer, 2010a, 2010b) and more 
false recognitions (Peters, Jelicic, Verbeek, \& Merckelbach, 2007).

The relationship between WMC and recall performance has also been examined in the context of eyewitness memory. For example, in an experiment by Jaschinski and Wentura (2002), participants watched a film depicting a staged crime. Next, they read a narrative about the film that contained both correct information and misleading information. The authors found that individuals with higher WMC (as measured with the Operation span task; Turner \& Engle, 1989) were less susceptible to the misinformation effect (i.e., were less likely to report the misleading information). Similar results were obtained when memory for misinformation was assessed in a recognition test (Zhu et al., 2010). Another eyewitness study examined proneness to intrusions (i.e., the reporting of non-pictured details) as a function of WMC (Gerrie \& Garry, 2007). In that study, participants with high WMC exhibited a lower false recognition rate of crucial details than participants with low WMC.

So far, eyewitness studies examining the relationship between cognitive factors and memory performance have focused on how low WMC is related to memory errors. From a practical point of view and in line with a positive psychological approach (see also Meissner, Hartwig, \& Russano, 2010), an important question is whether there are ways to remedy the performance deficit of people with lower WMC and source monitoring abilities. In fact, there are many groups of potential witnesses who are characterised by reduced levels of WMC and source monitoring, including individuals with lower intelligence (Engle et al., 1999), the elderly (Johnson et al., 1993; Salthouse, 1994), or individuals with particular mental disorders (e.g., Abraham, Windmann, McKenna, \& Güntürkün, 2007; Marchetta, Hurks, Krabbendam, \& Jolles, 2008). The aim of the present study was to test the effectiveness of retrieval support in individuals with different levels of WMC and source monitoring. Retrieval support refers to techniques that facilitate retrieval and help the witness during recall. One such technique is mental context reinstatement, which is part of the Cognitive Interview (CI; Fisher \& Geiselman, 1992). It is based on the principle of encoding specificity (Tulving \& Thomson, 1973) which proposes that recall is improved to the extent that encoding context is recreated, or reinstated, during retrieval. To this end, witnesses are instructed to think back to what they saw, heard, thought and felt when witnessing the incident. These contextual cues are stored parallel to the memory of the incident and promote retrieval by providing additional access pathways to the memory (see also network models of memory; Anderson, 1983).

Another interview that provides extensive retrieval support is the recently developed SelfAdministered Interview (SAI@); Gabbert, Hope, \& Fisher, 2009; Hope, Gabbert, \& Fisher, 2011). This interview format is independently completed by witnesses at the crime scene so as to elicit an early comprehensive statement when the police do not have the time to conduct an immediate personal interview. The SAI $\odot$ is based on the Cognitive Interview (Fisher \& Geiselman, 1992) and uses some of its memory-enhancing components, such as the mental context reinstatement and the "report-everything" instruction (i.e., the instruction to provide the most complete and accurate account possible). The SAIC includes non-leading questions and discourages witnesses from guessing. It consists of different sections each focusing on a different topic (e.g., course of events, appearance of the perpetrator) and hence provides a strong structure for recall. Furthermore, recall of spatial information is facilitated by asking witnesses to provide a sketch of the scene. Thus, the SAI@ makes use of multiple and varied retrieval, which has been proven beneficial for recall performance because details that cannot be accessed with one method may well become accessible with another one (Tulving \& Watkins, 1975). It has been found that the SAI@ induces a more comprehensive account than a control interview (i.e., a free recall), without compromising accuracy (Gabbert et al., 2009; Gawrylowicz, Memon, \& Scoboria, 2014; Krix, Sauerland, Gabbert, \& Hope, 2014), and can preserve memory for a subsequent interview (Hope, Gabbert, Fisher, \& Jamieson, 2014; Krix et al., 2014).

Previous eyewitness research that took into account individual differences in cognitive measures, such as WMC, either focused on only a small part of eyewitness testimony (i.e., reporting of misinformation; Jaschinski \& Wentura, 2002; Zhu et al., 2010) or used recognition tests (Gerrie \& Garry, 2007; Zhu et al., 2010) that are far removed from eyewitness interviews employed in normal police practice. With this in mind, the present study relied on an eyewitness paradigm that resembles real-life situations more closely to examine the relationship between working and source memory abilities and memory performance.

We considered the SAIC as a proxy tool for providing witnesses with retrieval support. Free 
recall, which simply instructs people to provide a free narrative of the incident and does not feature memory-enhancing components, was selected as a format that does not provide retrieval support. We examined whether relative to individuals with high WMC and source monitoring abilities, individuals with lower WMC and source monitoring abilities would benefit more from retrieval support than from free recall. We expected that interviews providing high levels of retrieval support (such as the SAI(C) may aid executive attention. More specifically, the SAIC with its different sections each focusing on a distinct topic may provide more structure during recall than free recall interviews. This may help focus attention on the recall task and suppress irrelevant information. Furthermore, the retrieval cues provided in interviews with ample retrieval support may directly help access information from long-term memory. Finally, the cues may also help compensate difficulties with keeping in mind what else one still wants to recall and help not to forget recalling certain aspects of the incident (e.g., clothing of the perpetrator). In doing so, retrieval support may attenuate the consequences of attentional deficits associated with lower WMC.

Source monitoring is dependent on the quality of the encoded information, as well as on the quality of the retrieved information and of the judgement processes (Johnson et al., 1993). Whereas the quality of the encoded information is beyond the influence of manipulations during the retrieval phase, at least the quality of the retrieval and judgement parts of source monitoring should be accessible for manipulations of the interview type. Unlike free recall, the SAIC provides context cues that facilitate the retrieval process (Tulving \& Thomson, 1973). Context cues are stored alongside the target event and provide additional pathways to get access to the recollection (Smith, 1994). Indeed, it has been suggested that context reinstatement may therefore facilitate source monitoring (Memon, Zaragoza, Clifford, \& Kidd, 2010). Because improved source monitoring aids retrieval, especially individuals who have difficulties with source monitoring should benefit from context reinstatement.

Thus, by assisting executive attention and facilitating source monitoring, retrieval support should be beneficial to individuals with lower WMC and source monitoring abilities when they try to recall complex information. Hence, we expected an interaction between presence of retrieval support and level of WMC and source monitoring abilities. More specifically, in the free recall group, we expected a positive association between WMC and source monitoring performance and both number of correct details and accuracy. A negative association was expected between WMC and source monitoring performance and number of incorrect details. For the group receiving retrieval support with the SAI@ $\odot$, we expected lower or null correlations between WMC and source monitoring performance and number of correct details, number of incorrect details and accuracy.

\section{METHOD}

\section{Design}

The present study is an overarching analysis and combines data from two experiments (Experiment 1: $n=88$; Experiment 2: $n=81$; reported in Krix et al., 2014). In both experiments, participants were tested individually and randomly assigned to the interview conditions, receiving either an SAI $\odot$ or a free recall as the recall tool. Hence, a betweenparticipants design was employed with presence or absence of retrieval support (retrieval support with the SAIC vs. free recall) as the independent variable. The WMC and source memory measures (which have not been reported previously) were consistently collected in both experiments.

Of note, in Experiment 1, half of the participants $(n=44)$ watched the stimulus film with divided attention. These were excluded from the current analyses for the following reasons. The divided attention manipulation impaired subsequent recall performance (see Krix et al., 2014, for a comprehensive description of methodology and findings). As distraction disrupts encoding, the quality of the stored information is degraded (Craik, Govoni, Naveh-Benjamin, \& Anderson, 1996). Therefore, the retrieval advantage of individuals with higher WMC and source monitoring abilities can take less effect. This is likely to distort the differences between participants with high and low levels of working and source memory, by making their recall performance more similar. Such equalisation may eventually obscure the relationship between recall performance and scores in the cognitive tasks.

\section{Participants}

The resulting sample comprised $N=125$ participants (91 women, 34 men; $M_{\text {age }}=22.51, S D_{\text {age }}=$ 5.84, range: $18-64, \operatorname{Mdn}=21$ years), with $n=44$ 
(SAIC: $n=22$, free recall: $n=22$ ) participants from Experiment 1 and $n=81$ (SAIC): $n=41$, free recall: $n=40$ ) participants from Experiment 2 . The pattern of recall performance was analogous across both experiments (see Krix et al., 2014). Participants were native speakers of German $(n=$ $101)$ or Dutch $(n=24)$. They were psychology undergraduates $(85 \%)$, students of other areas of study $(12 \%)$, or were recruited from the general public (3\%). Note that the samples of Experiment 1 and 2 did not differ with regard to mean age, $F(1,123)=0.56, p=.454$, gender, $p=.999$ (twosided; Fisher's exact test), and occupation (student vs. non-student), $p=.125$ (two-sided; Fisher's exact test). Participants received course credit or a $15 €$ voucher in exchange for participation. Inclusion criteria were German or Dutch as the native language and an age of 18-65 years.

\section{Materials}

\section{Stimulus film}

The non-violent stimulus film, presented without audio track, lasted 3:14 min and showed the staged theft of a laptop. Six amateur actors (four men and two women, aged 21-36) appeared in the film. The scene was situated at a communal area at a university. One student left his laptop unattended, whereupon the thief, incited by the accomplice, stole it and both left the scene.

\section{Recall tools: eyewitness interviews}

$S A I \odot$. German and Dutch translations of the original English version of the SAI@ (Gabbert et al., 2009; see Hope et al., 2011, for a detailed description) were used (see Krix et al., 2014, for previous use of these materials). First, witnesses were asked to mentally reinstate the context. That is, they were instructed to think back to the witnessed incident and picture what they could see or hear, and what they thought or felt at the time. Hereafter, witnesses described the course of events. In subsequent sections, non-leading cues were used to prompt descriptions of the appearance of the perpetrator(s), and, if applicable, of potential other witnesses or vehicles involved. Witnesses were also asked to draw a sketch of the scene, so as to facilitate recall of positions and directions (i.e., spatial information). Accordingly, the SAI $\odot$ relied on multiple and varied retrieval. In the final sections, details relating to the witnessing conditions (e.g., lighting conditions) were prompted and witnesses had the opportunity to write down any other information that came to mind. In every section, witnesses were reminded to provide the most complete and accurate account of the witnessed incident, but not to guess.

Free recall. Following Gabbert et al. (2009), in the free recall form, witnesses were merely requested to provide a description of the sequence of actions and events and a description of all persons involved, including the perpetrator(s) and other witnesses. As in the SAI $\odot$, participants were reminded to provide the most complete and accurate account possible, but not to guess. In contrast to the SAIC, the free recall lacked memory-enhancing components (e.g., mental context reinstatement). It entailed only one instead of multiple and varied retrieval attempts and did not provide prompts to cue recall.

\section{Working memory test: Operation span task}

As a measure of WMC, the Operation span (Ospan) task required participants to pursue a secondary task, when remembering items (Engle, Cantor, \& Carullo, 1992; Turner \& Engle, 1989). Specifically, participants solved arithmetic problems, when remembering words. They were presented with operation strings, that is, equationword pairs (e.g., "Is (10/5)-3=2? PAINT"). They had to read aloud the equation and subsequently determine by mental arithmetic, whether the suggested solution was correct or incorrect. Hereafter, participants read aloud the to-be-remembered word whereupon the next equation-word pair appeared. After the last operation string, three question marks appeared on screen, which marked the end of a trial and was the prompt for participants to write down the to-be-remembered words from the previous trial. Set size (i.e., number of equationword pairs) of a given trial varied from two to five. For each set size, there were three trials, yielding 12 trials in total. Set size varied pseudo-randomly. We used the partial-credit unit scoring to quantify performance (Conway et al., 2005). That is, a correctly recalled word was considered a correct response, irrespective of whether the word had been recalled in the correct order. Subsequently, average accuracy across trials was calculated.

\section{Source monitoring tests}

In line with Unsworth and Brewer (2010a), two source monitoring tests were used to measure source memory performance. 
Picture source monitoring. In the picture source monitoring test, participants were shown 30 pictures that appeared for $1 \mathrm{~s}$, one at a time, in one of four quadrants on screen. Participants were instructed to pay attention to both the picture and the quadrant in which the picture appeared. At test, they were presented with 30 old and 30 new pictures, each displayed in the centre of the screen. Participants had to indicate, whether a picture was old or new. If considered old, they were asked to specify in which quadrant it had appeared. The pictures were taken from Rossion and Pourtois (2004).

Gender source monitoring. In the gender source monitoring test, participants heard 30 English onesyllable nouns, which were spoken by either a female or male voice. They were instructed to pay attention to both the word and the gender of the voice. At test, participants were presented with 30 old and 30 new words that were shown to them on screen. They were instructed to indicate, whether a word was old or new. If considered old, they had to specify whether it had been spoken by the male or the female voice.

For both tests, the order of the stimuli during encoding and at test had initially been randomly determined and the same order was then applied to all participants. No time limits were imposed on the responses. However, after $5 \mathrm{~s}$ had elapsed without a response, a warning appeared urging participants to respond faster. For each participant, two scores were calculated, a picture source monitoring score and a gender source monitoring score. As in Unsworth and Brewer (2010a), the score was the proportion of correct responses across all items of each task. ${ }^{1}$

\footnotetext{
${ }^{1}$ We also calculated conditionalised source identification scores (i.e., the ratio of the number of correct source identifications of all old items correctly identified as old; Unsworth \& Brewer, 2009). Unlike proportion correct, this score only considers the old items. Replicating previous findings (Nash Unsworth, personal communication, April $25,2014)$, correlations between proportion correct and conditionalised scores were high (picture source: $r$ [123] = .91 ; gender source: $r[123]=.81$, ps $<.001)$. Entering the conditionalized scores into the regression equations yielded analogous results as the equations with the proportion correct scores. Only the interaction between gender source monitoring score and presence of retrieval support on the number of incorrect details changed from significant to marginally significant $(p=.059)$. The proportion correct score is reported in this manuscript as it has the advantage that it uses information from all test items.
}

\section{Procedure}

Approval for the experiments was obtained by the local ethics committee of the faculty. We made use of a cover story telling participants that the research dealt with social perception. After signing an informed consent and providing demographic information, participants were shown the stimulus film and were asked to watch carefully. The film was presented on a 22 in. $(55.88 \mathrm{~cm})$ screen with a resolution of $1920 \times 1080$ pixels. Hereafter, the working memory (Ospan) and source monitoring tests were completed, which were computer-based and run with E-Prime 1.1.4.1 and Presentation 14.8 , respectively. Participants were then taken to a different room to avoid effects of physical context on recall performance. Approximately 30 min after watching the film, they completed their interviews, either an SAIC or a free recall, depending on the retrieval support condition. After finishing data collection, participants were fully debriefed.

\section{Coding}

Following previous SAIC studies (Gabbert et al., 2009; Hope et al., 2014), participants' statements were transcribed and coded against a detailed coding scheme. For example, the statement "The thief sat at the table on the right" would yield four details (for further details see Krix et al., 2014; see also Sauerland, Krix, van Kan, Glunz, \& Sak, 2014). Subjective responses, such as "He was attractive", were not scored. A detail was coded as correct, if it matched the content of the film, and coded as incorrect, if it did not. Confabulations were defined as incorrect details referring to non-existent details (e.g., the thief attacked the victim; see Dando, Wilcock, \& Milne, 2009). To code the accuracy of age, height and weight estimates, we accepted deviations of 2 years, $4 \mathrm{~cm}$ or $3 \mathrm{~kg}$ from the true value (see Fahsing, Ask, \& Granhag, 2004). In the SAIC, information from the sketch was also coded. As was the case for verbal recall, a-priori coding rules were also specified for non-verbal output. Specifically, objects and their positions as well as the positions and moving directions (in the SAIC, witnesses are informed that they may use arrows for indicating directions) of the persons drawn in the sketch were scored. Only objects and persons that were labelled (e.g., thief) by the participant in the sketch were coded. Not all participants used labels 
and generally, the sketches yielded only few extra details relative to the other sections.

Regarding inter-coder reliability, the randomly selected statements of 10 Dutch and 10 German statements (i.e., 20 statements in total) were independently coded by two coders (see Krix et al., 2014). There was high agreement for correct (German: $\kappa=.99$; Dutch: $\kappa=.98 ; p \mathrm{~s} \leq .001$ ) and incorrect recall (German: $\kappa=.98$; Dutch: $\kappa=.94 ; p \mathrm{~s}$ $\leq .001)$.

\section{RESULTS}

In line with the recommendations provided by Conway et al. (2005) and to ensure that enough attention was paid to the verification element of the Ospan task, participants whose accuracy rate was less than $85 \%(n=5)$ in the verification element were excluded from analysis (note that this had no overall effect on the results). Unfortunately, the number of calculation errors was only available for participants from Experiment 2, but not for those from Experiment 1. Hence, participants from Experiment 1 who failed to pass the $85 \%$ accuracy limit in the verification element could not be identified and removed from the sample. $^{2}$

In the Ospan task, the average memory scores obtained were $M=80.93 \% \quad(S D=8.65$; range = $48.47 \%-98.33 \%)$. For the picture and gender source test, the average scores were $M=82.51 \%$ $(S D=9.20 ;$ range $=55.00 \%-98.33 \%)$ and $M=$ $65.44 \%(S D=10.36$; range $=40.00 \%-95.00 \%)$, respectively. Performance in the Ospan task was not correlated with performance in the picture source monitoring score, $r(118)=-.09, p=.337$, but positively correlated with the gender source monitoring score, $r(118)=.23, p=.012$. The

\footnotetext{
${ }^{2}$ Although the missing of these data is not optimal, we do not believe that our results were influenced for the following reasons. First, even though the cases from Experiment 2 that were removed scored rather low in the Ospan task (percentile ranks ranging from $2.5 \%$ to $39.5 \%$ of the Experiment 2 sample), they were by no means outliers. As the sample of Experiment 1 was in many ways comparable to the sample of Experiment 2, there is no reason to believe that patterns would have been different in Experiment 1. Second, usually a very small fraction of participants is affected by an excessive number of errors (Kane \& Engle, 2000; Turner \& Engle, 1989). Third, and most importantly, previous research found that the pattern of correlations of the Ospan score with other working memory measures remained unaffected after participants with an accuracy rate of less than $85 \%$ were excluded from analysis (Unsworth, Heitz, Schrock, \& Engle, 2005).
}

correlation between picture and gender source monitoring scores was $r(123)=.07, p=.430$.

We performed multiple regression analyses (enter method) on the data. As predictors, a dummy variable to code for the presence of retrieval support (retrieval support $=1$; free recall $=0$ ), the centred Ospan and source monitoring scores, and the interaction terms were entered into the equations (i.e., seven predictors in total). An a-priori power analysis with $\mathrm{G}^{*}$ Power 3.1 (Faul, Erdfelder, Lang, \& Buchner, 2007) yielded a required total sample size of $N=103$ participants, given $\beta=.80, \alpha=.05$, and a medium effect size. The number of correct and incorrect details and accuracy (number of correct details divided by all reported details; see Meissner, Sporer, \& Susa, 2008) were the dependent variables. When the interaction terms were significant, we analysed the simple slopes of both interview groups. When the interaction terms were non-significant, they were removed one at a time and the analyses re-run until only significant interaction terms or main effects remained. Table 1 shows the means and standard deviations of the recall performance for the retrieval support and the free recall group. Table 2 shows the results of the final regression equations, after non-significant interactions were removed.

\section{Working memory capacity (Ospan score) and presence of retrieval support}

We expected an interaction between WMC as measured with the Ospan task and presence of retrieval support. That is, in the free recall group, the Ospan score was expected to be positively related to the number of correct details and

TABLE 1

Means and standard deviations for number of correct and incorrect details, and accuracy as a function of presence of retrieval support

\begin{tabular}{lrrrrr}
\hline & \multicolumn{2}{c}{$\begin{array}{c}\text { Free recall } \\
(n=62)\end{array}$} & & \multicolumn{2}{c}{$\begin{array}{c}\text { Retrieval support } \\
(n=63)\end{array}$} \\
\cline { 2 - 3 } \cline { 6 - 7 } & $\mathrm{M}$ & $\mathrm{SD}$ & & $\mathrm{M}$ & $\mathrm{SD}$ \\
\hline Correct details & 85.89 & 24.52 & & 117.16 & 28.20 \\
Incorrect details & 10.06 & 5.16 & & 14.43 & 5.72 \\
Accuracy (\%) & 89.55 & 4.59 & & 88.83 & 4.37 \\
\hline
\end{tabular}

The means and standard deviations reported in this table result from a combination of the recall data of Experiment 1 and Experiment 2 reported in Krix et al. (2014). 
TABLE 2

Regression of recall performance on Ospan and picture and gender source monitoring score, and presence of retrieval support

\begin{tabular}{|c|c|c|c|c|c|c|c|c|c|}
\hline Variable & B & $95 \% C I(\mathrm{~B})$ & SE & $\beta$ & $\mathrm{t}$ & $\mathrm{p}$ & $\mathrm{R}^{2}$ & $95 \% C I\left(\mathrm{R}^{2}\right)$ & $\mathrm{F}$ \\
\hline Correct details & & & & & & & .30 & {$[.17, .43]$} & $12.07 * *$ \\
\hline D1 & 31.01 & {$[21.39,40.62]$} & 4.85 & .50 & 6.39 & $<.001$ & & & \\
\hline Ospan & 30.97 & {$[-26.56,88.49]$} & 29.04 & .09 & 1.07 & .289 & & & \\
\hline Picture source & 64.42 & {$[11.58,117.26]$} & 26.68 & .19 & 2.42 & .017 & & & \\
\hline Gender source & -11.71 & {$[-59.01,35.59]$} & 23.88 & -.04 & -0.49 & .625 & & & \\
\hline Incorrect details & & & & & & & .23 & {$[.10, .36]$} & $6.87 * *$ \\
\hline D1 & 4.66 & {$[2.72,6.60]$} & 0.98 & .39 & 4.76 & $<.001$ & & & \\
\hline Ospan & 6.15 & {$[-5.45,17.75]$} & 5.86 & .09 & 1.05 & .296 & & & \\
\hline Picture source & -4.83 & {$[-15.48,5.83]$} & 5.38 & -.07 & -0.90 & .372 & & & \\
\hline Gender source & 10.32 & {$[-3.20,23.84]$} & 6.82 & .18 & 1.51 & .133 & & & \\
\hline Gender source $\times$ D1 & -29.99 & {$[-48.51,-11.47]$} & 9.35 & -.38 & -3.21 & .002 & & & \\
\hline Accuracy & & & & & & & .13 & {$[.02, .24]$} & $3.45^{*}$ \\
\hline D1 & -0.01 & {$[-0.03,0.01]$} & 0.01 & -.10 & -1.18 & .241 & & & \\
\hline Ospan & -0.02 & {$[-0.11,0.08]$} & 0.05 & -.03 & -0.37 & .711 & & & \\
\hline Picture source & 0.09 & {$[<0.01,0.17]$} & 0.04 & .18 & 2.02 & .046 & & & \\
\hline Gender source & -0.14 & {$[-0.25,-0.03]$} & 0.06 & -.31 & -2.45 & .016 & & & \\
\hline Gender source $\times$ D1 & 0.26 & {$[0.11,0.41]$} & 0.08 & .44 & 3.47 & .001 & & & \\
\hline
\end{tabular}

$\mathrm{D} 1=$ dummy variable to code for the presence of retrieval support.

$* p<.01 ; * p<.001$.

accuracy and negatively related to the number of incorrect details. In the retrieval support group, no significant associations of Ospan score and recall performance should emerge. However, all interactions were non-significant, $|B| \mathrm{s} \leq 27.05,|\beta| \mathrm{s} \leq .06$, $p s \geq .650$, and there were no significant main effects of the Ospan score after removing the interaction terms, either, $p s \leq .289$ (see Table 2).

\section{Source monitoring ability and presence of retrieval support}

As for WMC, we expected an interaction between source monitoring abilities and presence of retrieval support. That is, in the free recall group, the source monitoring scores should be positively related to the number of correct details and accuracy and negatively related to the number of incorrect details. In the retrieval support group, no significant associations of source monitoring scores and recall performance should emerge.

\section{Number of correct details}

In contrast to our hypotheses, we did not find any significant interactions of presence of retrieval support with the picture source monitoring score, $B=66.27,95 \%$ CI $[-39.50,172.04], S E=53.39$, $\beta=.13, p=.217$, or the gender source monitoring score, $B=21.83$, 95\% CI [-70.25, 113.92], $S E=$ $46.48, \beta=.05, p=.639$. As can be derived from the positive regression coefficient in Table 2, irrespective of the presence of retrieval support, a higher picture source monitoring score was associated with the recall of more correct details $(p=.017)$. The main effect of the gender source monitoring score was non-significant $(p=.625)$.

\section{Number of incorrect details}

The interaction between presence of retrieval support and picture source monitoring score was not significant, $B=-8.13,95 \%$ CI $[-29.58,13.32]$, $S E=10.83, \beta=-.08, p=.454$. The same held for the main effect of the picture source monitoring score, $p=.372$ (see Table 2).

The interaction between presence of retrieval support and gender source monitoring score was significant, $B=-29.99,95 \%$ CI [-48.51, -11.47], $S E=9.35, \beta=-.38, p=.002$. Although the interaction was significant, the analyses of the simple slopes revealed a pattern that was exactly the opposite of the expected pattern. More specifically, the analyses of the simple slopes yielded a non-significant effect for the free recall group, $B=$ $10.32,95 \%$ CI $[-3.20,23.84], S E=6.82, \beta=.18$, $p=.133$. For the retrieval support group, in contrast, a negative association emerged such that a higher gender source monitoring score was associated with the recall of fewer incorrect details, $B=-19.67,95 \%$ CI $[-32.75,-6.60], S E$ $=6.60, \beta=-.35, p=.004$. Figure 1 displays the results of this simple slope analysis for the number of incorrect details. 


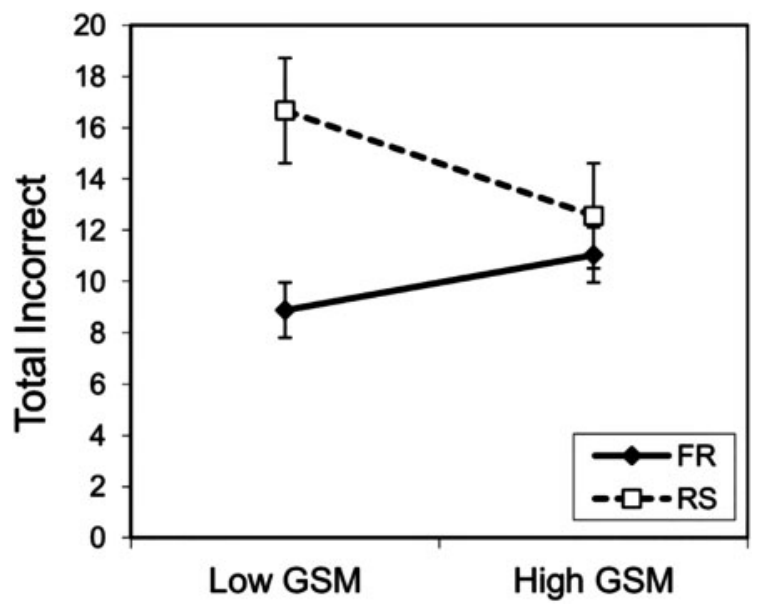

Figure 1. Simple slopes of the interaction between gender source monitoring score and presence of retrieval support for the number of incorrect details. Low and high source monitoring is defined as $1 S D$ below or above the mean score. RS = retrieval support; FR = free recall; GSM = gender source monitoring.

\section{Accuracy}

As with correct and incorrect details, there was no significant interaction between the picture source monitoring score and presence of retrieval support, $B=0.15,95 \%$ CI $[-0.02,0.33], S E=0.09, \beta=$ $.21, p=.080$, although a higher picture source monitoring score was associated with higher recall accuracy, $p=.046$ (see Table 2).

The interaction between presence of retrieval support and gender source monitoring score was significant, $B=0.26,95 \%$ CI [0.11, 0.41], $S E=$ $0.08, \beta=.44, p=.001$. As with incorrect recall, the analysis of the simple slopes yielded results opposite to the expected pattern. That is, for the free recall group, a lower gender source monitoring score was associated with a higher accuracy, $B=$ $-0.14,95 \%$ CI $[-0.25,-0.03], S E=0.06, \beta=-.31$, $p=.016$. In contrast, for the retrieval support group, a lower gender source monitoring score was associated with lower accuracy, $B=0.13,95 \%$ CI [0.02, 0.23], $S E=0.05, \beta=.29, p=.019$. Figure 2 displays the results of this simple slope analysis for recall accuracy.

\section{DISCUSSION}

In the present study, we sought to extend the existing research on the relationship between working memory and source monitoring and recall performance within the context of eyewitness testimony. More specifically, the aim of the

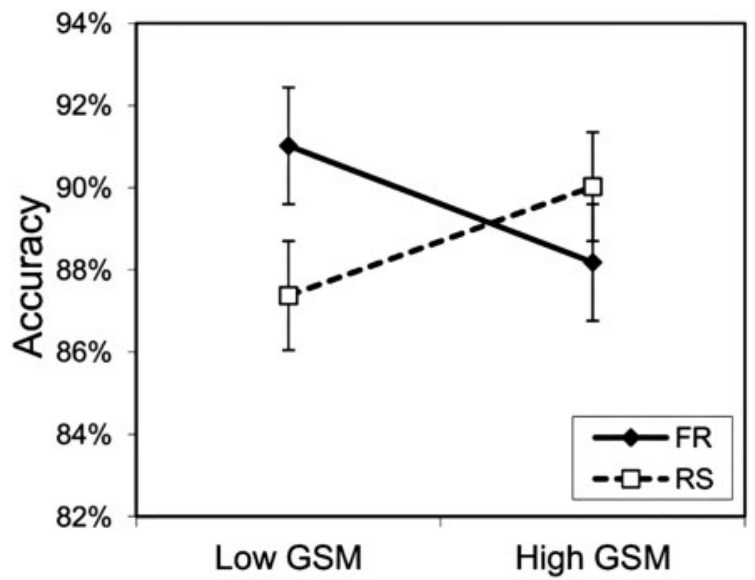

Figure 2. Simple slopes of the interaction between gender source monitoring score and presence of retrieval support for accuracy. Low and high source monitoring is defined as $1 S D$ below or above the mean score. $\mathrm{RS}=$ retrieval support; $\mathrm{FR}=$ free recall; GSM = gender source monitoring.

present study was to examine the effect of retrieval support in witnesses with different levels of WMC and source monitoring abilities on recall performance. The recently developed SAI@ (Gabbert et al., 2009) was selected as a proxy tool for providing witnesses with retrieval support. We hypothesised that retrieval support, not free recall, would be especially beneficial for individuals with lower relative to higher WMC or source monitoring abilities.

In contrast to our hypotheses, there were no significant interactions between presence of retrieval support and WMC to predict recall performance. This suggests that the greater structure provided by retrieval support may not be a suitable means to compensate deficits in executive attention found in individuals with lower WMC (Engle et al., 1999; Engle \& Kane, 2004). Given that the SAIC already entailed a considerable amount of retrieval support, it is unlikely that a further increase in retrieval support would have brought about a significant change of the pattern of results. We had reasoned that the greater structure provided in the SAI@ because of its different recall sections would help witnesses focus on the current recall task and suppress irrelevant information. Furthermore, the retrieval cues should help access the memory and keep in mind what else one wants to recall. As described in the introduction, attending to relevant information and holding current task goals active are not the only activities working memory is involved in (Engle et al., 1999; Engle \& Kane, 2004). 
Although speculative, it may be the case that holding the retrieved information active and monitoring previous output required so much executive attention that the retrieval support did not provide sufficient compensation.

The question could be raised whether retrieval support with the SAI $\odot$ may actually have increased cognitive load. One argument in favour of this could be that the more comprehensive recall instructions used in the SAIC may have been more difficult to memorise than those used in the free recall. However, we do not think that retrieval support with the SAIC led to elevated levels of cognitive load. If anything, the SAIC reduces the necessity to memorise instructions. As it is a written interview, the instructions are always visible to the witnesses and can be reread at the witnesses' own pace if necessary. Consequently, the influence of instruction comprehensiveness on cognitive load should be reduced. Furthermore, the SAIC is completed in the absence of an interviewer. The presence of others has been found to increase cognitive load and to impair performance in tasks involving frontal activity (Wagstaff et al., 2008). Retrieval from memory is such a task (Kane \& Engle, 2002). Hence, two important components often found in interviews that lead to increased cognitive load are simply absent in the SAIC. More importantly, the notion that the SAI@ induced higher cognitive load than free recall was not supported by the data. If retrieval support with the SAIC had increased cognitive load relative to free recall, a significant interaction opposite to the hypothesised pattern would have emerged. More specifically, a significant positive relationship between WMC and recall performance in the retrieval support group and a non-significant relationship between WMC and recall performance in the free recall group would have been observed. This pattern should have emerged because in the interview condition imposing less cognitive load (i.e., free recall in this example), recall performance of individuals with higher and lower WMC should hardly differ, hence the obscured relationship between WMC and recall performance. The reason for this is that under low cognitive load the available cognitive capacity of participants with lower WMC may still be sufficient to adequately retrieve information, because working memory is occupied only little by other tasks (e.g., memorising instructions). When the interview imposes high cognitive load (i.e., the SAIC in this example), however, individuals with lower WMC may quickly experience overload and have not enough remaining capacity to adequately retrieve information from memory. On the other hand, the capacity of individuals with higher WMC may still be sufficient to correctly retrieve information in this situation. Consequently, individuals with higher WMC should exhibit better recall performance than individuals with lower WMC (i.e., a positive relationship between WMC and recall performance). However, no significant interactions were obtained. So whereas the SAI@ did not reduce cognitive load relative to free recall, it did not seem to increase it, either. The question could arise, whether using the related Cognitive Interview instead of the SAIC as a proxy tool for ample retrieval support would have yielded more positive results. We deem this unlikely, because the Cognitive Interview probably induces higher cognitive load than the SAIC given that it involves an interviewer and that the possibility to review the instructions is limited (i.e., participants usually hear the instructions only once).

Since WMC did not predict recall performance in the present study at all (i.e., there were no significant main effects, either), our findings should, perhaps, be considered with caution. There is no obvious reason for these non-significant results. Previous studies also involving homogenous samples of undergraduates have identified associations between WMC as measured with the Ospan task and memory performance (Gerrie \& Garry, 2007; Jaschinski \& Wentura, 2002; but see Peters et al., 2007, who did not find a relation between memory performance and Ospan score within an undergraduate sample). Unfortunately, we could not compare the ranges throughout, as Jaschinski and Wentura (2002) did not report them. Moreover, Gerrie and Garry (2007) employed the computerised version of the Ospan task that uses different stimuli and hence precludes a direct comparison of the scores. Yet, in the studies that allowed comparisons (Peters et al., 2007; Sauerland et al., 2014, Experiment 1), the mean and range of the Ospan scores were similar to those obtained here. In the absence of established norms for the paper-pencil Ospan task, this suggests that the mean and range found here may be typical of undergraduate samples.

With respect to source monitoring performance, the hypotheses were not supported, either. Specifically, for the gender source monitoring test, we found results opposite to the expected pattern. That is, in the retrieval support group, a higher gender source monitoring score was associated 
with fewer recall errors and more accurate reports. In contrast, in the free recall group, a lower score was associated with more accurate reports. Although there were no interactions between presence of retrieval support and the picture source monitoring score, we obtained the usual pattern that better source monitoring was associated with better recall performance. Unlike previous findings (Unsworth \& Brewer, 2010a), this pattern was not due to fewer errors, but due to recall of more correct details. It is noteworthy that the two source monitoring tasks were not correlated and yielded different results. The former contradicts previous studies in which the two tasks were significantly correlated and loaded on a source memory factor that was distinct from other factors, such as working memory (Sauerland et al., 2014; Unsworth \& Brewer, 2010a). We can only speculate about this discrepancy regarding the correlation pattern, especially given the analogous sample compositions and similar means and ranges. As to the divergent findings in the picture and gender source monitoring tasks, the modality may have played a role. The interaction occurred for the gender source monitoring task that, as the recall task, is a verbal task. Matching the modality may be more diagnostic of the demands of the recall task and would seem to suggest that modality needs to be considered when relating source monitoring ability to other performance. This explanation, however, does not fully capture the pattern of results, because the visual picture source monitoring task also predicted verbal recall performance, albeit across interviews. It is also conceivable that the non-significant interaction regarding the picture source monitoring task simply constituted an outlier. Recent replication reports show that effect sizes can vary and outliers do occur (Alogna et al., 2014).

Contrary to previous assumptions (Memon et al., 2010), it thus seems that providing witnesses with retrieval support did not facilitate source monitoring. Importantly, our results are consistent with findings obtained in a sample with autism spectrum disorders (ASD), a condition known to be associated with reduced source monitoring performance (Bowler, Gardiner, \& Berthollier, 2004). Specifically, in two studies, Maras and Bowler $(2010,2012)$ found that individuals with ASD did not benefit from recall with the CI and the use of mental context reinstatement in particular. When interviewed with a structured interview that lacked mental context reinstatement, no differences emerged between participants with
ASD and participants without ASD. Source monitoring is dependent not only on the quality of the retrieved information and of the judgement processes, but also on the quality of the encoded information (Johnson et al., 1993). To the extent that the latter of these three factors is decisive for successful source monitoring, providing retrieval support that is targeted on the retrieval phase is unlikely to enhance remembering. Indeed, problems with source monitoring have been related to binding deficits during encoding (Chalfonte \& Johnson, 1996). These refer to problems in binding details of the target event with feature information necessary to specify the source, such as spatial or temporal (i.e., context) information (see also the Constructive Memory Framework; Schacter et al., 1998). For successful mental context reinstatement, however, intact connections between context cues and details of the target event are essential. If the context is not connected to the event, the context cues cannot provide access to the memory of the event (see Maras \& Bowler, 2012). Failure to establish the links during encoding could be the reason why mental context reinstatement may be ineffective for participants with lower source monitoring abilities. Therefore, retrieval support with the SAIC that, unlike free recall, made use of context reinstatement may not have had beneficial effects for the participants with lower source monitoring abilities. However, the advantage of retrieval support for individuals with high source monitoring abilities was observed for only the gender source monitoring task. As for the picture source monitoring task and recall performance, the interview type was irrelevant. Therefore, the interpretation of the source memory results should be considered with caution and we strongly encourage future research to explore these issues further. Corroborating our findings, however, a recent study by Maras, Mulcahy, Memon, Picariello, and Bowler (2014) suggests that providing retrieval support with the SAIC may not be an appropriate strategy for witnesses with ASD. Specifically, the SAIC elicited less accurate reports from participants with ASD than a control interview that lacked retrieval support components. This finding could mainly be attributed to the context reinstatement section of the SAIC. No such differences as a function of interview type emerged for the participants without ASD. As argued before (Maras \& Bowler, 2012), Maras et al. consider the deficits in executive functioning found in individuals with ASD to be responsible for the ineffectiveness of retrieval 
support with the SAIC and mental context reinstatement in particular.

Turning to the limitation of this study, the sample that was tested predominantly consisted of undergraduates. Indeed, it could be criticised that we did not test participants who were characterised by low WMC and source monitoring abilities (e.g., individuals with low intelligence). Moreover, testing undergraduates who cognitively functioned at a high level and were unlikely to differ much regarding cognitive tasks (see Peters et al., 2007) made the sample rather homogenous. Therefore, if anything, our findings probably underestimated the associations between WMC and source monitoring and recall performance. However, previous research found significant associations between cognitive measures and recall performance even in undergraduate samples (e.g., Jaschinski \& Wentura, 2002; Peters et al., 2007; Unsworth \& Brewer, 2010a, 2010b). Nevertheless, our findings require replication in mixed samples of people with low WMC and source memory (e.g., patient groups) and healthy people.

Apart from examining the relationship between retrieval support and WMC and source memory in a more diverse sample, there is a second research line that could be addressed in future research. Given that retrieval support was not effective, it should be the aim of future research to investigate whether there are other means to help witnesses with reduced WMC and source monitoring abilities remember and obtain highly accurate and complete accounts. The importance of such an endeavour is underlined by the fact that many victims of crimes are psychiatric patients (Walsh et al., 2003) who often have poor executive functioning (e.g., Abraham et al., 2007). We therefore urge further research on this important topic.

In conclusion, the results of the current study appear to suggest that providing retrieval support is not an effective means to help witnesses with lower WMC or source monitoring abilities remember. Whereas retrieval support seems to be equally effective for witnesses with high or low WMC, source monitoring ability appears to be critical for completing an interview with retrieval support that comprises mental context reinstatement. Witnesses with reduced source monitoring abilities may not benefit from mental context reinstatement during retrieval because of a deficit that already emerges in the encoding phase, that is, the failure to establish links between target and contextual information during encoding
(Chalfonte \& Johnson, 1996). As such, it may be prudent to advise caution when administering such interviews to witnesses with reduced source monitoring abilities. However, it is important to note that this is the first study to examine the interaction of retrieval support and WMC and source monitoring ability to predict eyewitness recall performance. Hence, replications are critical, especially with a more diverse sample than the one used here.

\section{REFERENCES}

Abraham, A., Windmann, S., McKenna, P., \& Güntürkün, O. (2007). Creative thinking in schizophrenia: The role of executive dysfunction and symptom severity. Cognitive Neuropsychiatry, 12, 235-258. doi:10.1080/13546800601046714

Alogna, V. K., Attaya, M. K., Aucoin, P., Bahnik, S., Birch, S., Birt, A. R., ... Zwaan, R. A. (2014). Registered replication report: Schooler and Engstler-Schooler (1990). Perspectives on Psychological Science, 9, 556-578. doi:10.1177/1745691614 545653

Anderson, J. R. (1983). A spreading activation theory of memory. Journal of Verbal Learning and Verbal Behavior, 22, 261-295. doi:10.1016/S0022-5371(83) 90201-3

Baddeley, A. (2000). The episodic buffer: a new component of working memory? Trends in Cognitive Sciences, 4, 417-423. doi:10.1016/S1364-6613(00)01538-2

Baddeley, A. (2010). Working memory. Current Biology, 20, R136-R140. doi:10.1016/j.cub.2009.12.014

Baddeley, A., Emslie, H., Kolodny, J., \& Duncan, J. (1998). Random generation and the executive control of working memory. The Quarterly Journal of Experimental Psychology Section A, 51, 819-852. doi:10.1080/713755788

Baddeley, A. D., \& Hitch, G. (1974). Working memory. In G. A. Bower (Ed.), The psychology of learning and motivation (pp. 47-89). New York, NY: Academic Press.

Bowler, D. M., Gardiner, J. M., \& Berthollier, N. (2004). Source memory in adolescents and adults with Asperger's syndrome. Journal of Autism and Developmental Disorders, 34, 533-542. doi:10.1007/s10803004-2548-7

Chalfonte, B. L., \& Johnson, M. K. (1996). Feature memory and binding in young and older adults. Memory \& Cognition, 24, 403-416. doi:10.3758/BF0 3200930

Conway, A. R. A., Kane, M. J., Bunting, M. F., Hambrick, D. Z., Wilhelm, O., Engle, R. W. (2005). Working memory span tasks: A methodological review and user's guide. Psychonomic Bulletin \& Review, 12, 769-786. doi:10.3758/BF03196772

Craik, F. I. M., Govoni, R., Naveh-Benjamin, M., \& Anderson, N. D. (1996). The effects of divided attention on encoding and retrieval processes in human memory. Journal of Experimental Psychology: General, 125, 159-180. doi:10.1037/0096-3445.125.2.159 
Dando, C., Wilcock, R., \& Milne, R. (2009). The Cognitive Interview: The efficacy of a modified mental reinstatement of context procedure for frontline police investigators. Applied Cognitive Psychology, 23(1), 138-147. doi:10.1002/acp.1451

Elliott, R. (2003). Executive functions and their disorders. British Medical Bulletin, 65(1), 49-59. doi:10 .1093/bmb/65.1.49

Engle, R. W., Cantor, J., \& Carullo, J. J. (1992). Individual differences in working memory and comprehension: A test of four hypotheses. Journal of Experimental Psychology: Learning, Memory, and Cognition, 18, 972-992. doi:10.1037/0278-7393.18. 5.972

Engle, R. W., \& Kane, M. J. (2004). Executive attention, working memory capacity, and a two-factor theory of cognitive control. In B. Ross (Ed.), The psychology of learning and motivation (Vol. 44, pp. 145-199). New York, NY: Elsevier.

Engle, R. W., Tuholski, S. W., Laughlin, J. E., \& Conway, A. R. A. (1999). Working memory, shortterm memory, and general fluid intelligence: A latent-variable approach. Journal of Experimental Psychology: General, 128, 309-331. doi:10.1037/00 96-3445.128.3.309

Fahsing, I. A., Ask, K., \& Granhag, P. A. (2004). The man behind the mask: Accuracy and predictors of eyewitness offender descriptions. Journal of Applied Psychology, 89, 722-729. doi:10.1037/0021-9010.89. 4.722

Faul, F., Erdfelder, E., Lang, A.-G., \& Buchner, A. (2007). G*Power 3: A flexible statistical power analysis program for the social, behavioral, and biomedical sciences. Behavior Research Methods, 39, 175-191. doi:10.3758/BF03193146

Fisher, R. P., \& Geiselman, R. E. (1992). Memory enhancing techniques for investigative interviewing: The cognitive interview. Springfield, IL: Charles C. Thomas.

Gabbert, F., Hope, L., \& Fisher, R. P. (2009). Protecting eyewitness evidence: Examining the efficacy of a Self-administered Interview tool. Law and Human Behavior, 33, 298-307. doi:10.1007/s10979-008-9146-8

Gawrylowicz, J., Memon, A., \& Scoboria, A. (2014). Equipping witnesses with transferable skills: The Self-administered Interview@. Psychology, Crime \& Law, 20, 315-325. doi:10.1080/1068316X.2013.777961

Gerrie, M. P., \& Garry, M. (2007). Individual differences in working memory capacity affect false memories for missing aspects of events. Memory, 15, 561571. doi:10.1080/09658210701391634

Hope, L., Gabbert, F., \& Fisher, R. P. (2011). From laboratory to the street: Capturing witness memory using the Self-administered Interview. Legal and Criminological Psychology, 16, 211-226. doi:10.1111/ j.2044-8333.2011.02015.x

Hope, L., Gabbert, F., Fisher, R. P., \& Jamieson, K. (2014). Protecting and enhancing eyewitness memory: The impact of an initial recall attempt on performance in an investigative interview. Applied Cognitive Psychology, 28, 304-313. doi:10.1002/ac p.2984

Jahanshahi, M., Saleem, T., Ho, A. K., Dirnberger, G., \& Fuller, R. (2006). Random number generation as an index of controlled processing. Neuropsychology, 20, 391-399. doi:10.1037/0894-4105.20.4.391

Jaschinski, U., \& Wentura, D. (2002). Misleading postevent information and working memory capacity: An individual differences approach to eyewitness memory. Applied Cognitive Psychology, 16, 223231. doi:10.1002/acp.783

Johnson, M. K., Hashtroudi, S., \& Lindsay, D. S. (1993). Source monitoring. Psychological Bulletin, 114(1), 328. doi:10.1037/0033-2909.114.1.3

Kane, M. J., \& Engle, R. W. (2000). Working-memory capacity, proactive interference, and divided attention: Limits on long-term memory retrieval. Journal of Experimental Psychology: Learning, Memory, and Cognition, 26, 336-358. doi:10.1037/0278-7393.26. 2.336

Kane, M. J., \& Engle, R. W. (2002). The role of prefrontal cortex in working-memory capacity, executive attention, and general fluid intelligence: An individual-differences perspective. Psychonomic Bulletin \& Review, 9, 637-671. doi:10.3758/BF03196323

Krix, A. C., Sauerland, M., Gabbert, F., \& Hope, L. (2014). Providing eyewitnesses with initial retrieval support: What works at immediate and subsequent recall? Psychology, Crime \& Law, 20, 1005-1027. doi:10.1080/1068316X.2014.902456

Maras, K. L., \& Bowler, D. M. (2010). The cognitive interview for eyewitnesses with autism spectrum disorder. Journal of Autism and Developmental Disorders, 40, 1350-1360. doi:10.1007/s10803-010-0997-8

Maras, K. L., \& Bowler, D. M. (2012). Context reinstatement effects on eyewitness memory in autism spectrum disorder. British Journal of Psychology, 103, 330-342. doi:10.1111/j.2044-8295.2011.02077.x

Maras, K. L., Mulcahy, S., Memon, A., Picariello, F., \& Bowler, D. M. (2014). Evaluating the effectiveness of the Self-administered Interview@ for witnesses with autism spectrum disorder. Applied Cognitive Psychology, 28, 693-701. doi:10.1002/acp.3055

Marchetta, N. D. J., Hurks, P. P. M., Krabbendam, L., \& Jolles, J. (2008). Interference control, working memory, concept shifting, and verbal fluency in adults with attention-deficit/hyperactivity disorder (ADHD). Neuropsychology, 22(1), 74-84. doi:10.1037/0894-410 5.22.1.74

McCabe, D. P., Roediger, H. L., McDaniel, M. A., Balota, D. A., \& Hambrick, D. Z. (2010). The relationship between working memory capacity and executive functioning: Evidence for a common executive attention construct. Neuropsychology, 24, 222243. doi:10.1037/a0017619

Meissner, C. A., Hartwig, M., \& Russano, M. B. (2010). The need for a positive psychological approach and collaborative effort for improving practice in the interrogation room. Law and Human Behavior, 34 (1), 43-45. doi:10.1007/s10979-009-9205-9

Meissner, C. A., Sporer, S. L., \& Susa, K. J. (2008). A theoretical review and meta-analysis of the description-identification relationship in memory for faces. European Journal of Cognitive Psychology, 20, 414455. doi:10.1080/09541440701728581

Memon, A., Zaragoza, M., Clifford, B. R., \& Kidd, L. (2010). Inoculation or antidote? The effects of cognitive interview timing on false memory for forcibly 
fabricated events. Law and Human Behavior, 34, 105-117. doi:10.1007/s10979-008-9172-6

Mitchell, K. J., Johnson, M. K., Raye, C. L., \& Greene, E. J. (2004). Prefrontal cortex activity associated with source monitoring in a working memory task. Journal of Cognitive Neuroscience, 16, 921-934. doi:10. 1162/0898929041502724

Peters, M. J. V., Jelicic, M., Verbeek, H., \& Merckelbach, H. (2007). Poor working memory predicts false memories. European Journal of Cognitive Psychology, 19, 213-232. doi:10.1080/09541440600760396

Rosen, V. M., \& Engle, R. W. (1997). The role of working memory capacity in retrieval. Journal of Experimental Psychology: General, 126, 211-227. doi:10.1037/0096-3445.126.3.211

Rossion, B., \& Pourtois, G. (2004). Revisiting Snodgrass and Vanderwart's object pictorial set: The role of surface detail in basic-level object recognition. Perception, 33, 217-236. doi:10.1068/p5117

Salthouse, T. A. (1994). The aging of working memory. Neuropsychology, 8, 535-543. doi:10.1037/0894-4105. 8.4.535

Sauerland, M., Krix, A. C., van Kan, N., Glunz, S., \& Sak, A. (2014). Speaking is silver, writing is golden? The role of cognitive and social factors in written versus spoken witness accounts. Memory \& Cognition, 42, 978-992. doi:10.3758/s13421-014-0401-6

Schacter, D. L., Norman, K. A., \& Koutstaal, W. (1998). The cognitive neuroscience of constructive memory. Annual Review of Psychology, 49, 289-318. doi:10.11 46/annurev.psych.49.1.289

Smith, S. M. (1994). Theoretical principles of contextdependent memory. In P. E. Morris \& M. Gruneberg (Eds.), Theoretical aspects of memory (pp. 168-195). London: Routledge.

Tulving, E., \& Thomson, D. M. (1973). Encoding specificity and retrieval processes in episodic memory. Psychological Review, 80, 352-373. doi:10.1037/ h0020071

Tulving, E., \& Watkins, M. J. (1975). Structure of memory traces. Psychological Review, 82, 261-275. doi:10.1037/h0076782

Turner, M. L., \& Engle, R. W. (1989). Is working memory capacity task dependent? Journal of Memory and Language, 28, 127-154. doi:10.1016/0749596X(89)90040-5
Unsworth, N., \& Brewer, G. A. (2009). Examining the relationships among item recognition, source recognition, and recall from an individual differences perspective. Journal of Experimental Psychology: Learning, Memory, and Cognition, 35, 1578-1585. doi:10.1037/a0017255

Unsworth, N., \& Brewer, G. A. (2010a). Individual differences in false recall: A latent variable analysis. Journal of Memory and Language, 62(1), 19-34. doi:10.1016/j.jml.2009.08.002

Unsworth, N., \& Brewer, G. A. (2010b). Variation in working memory capacity and intrusions: Differences in generation or editing? European Journal of Cognitive Psychology, 22, 990-1000. doi:10.1080/0954144 0903175086

Unsworth, N., \& Engle, R. W. (2007). The nature of individual differences in working memory capacity: Active maintenance in primary memory and controlled search from secondary memory. Psychological Review, 114(1), 104-132. doi:10.1037/0033-295 X.114.1.104

Unsworth, N., Heitz, R. P., Schrock, J. C., \& Engle, R. W. (2005). An automated version of the operation span task. Behavior Research Methods, 37, 498-505. doi:10.3758/BF03192720

Wagstaff, G. F., Wheatcroft, J., Cole, J. C., BrunasWagstaff, J., Blackmore, V., \& Pilkington, A. (2008). Some cognitive and neuropsychological aspects of social inhibition and facilitation. European Journal of Cognitive Psychology, 20, 828-846. doi:10.1080/095 41440701469749

Walsh, E., Moran, P., Scott, C., McKenzie, K., Burns, T., Creed, F., ... Fahy, T. (2003). Prevalence of violent victimisation in severe mental illness. The British Journal of Psychiatry, 183, 233-238. doi:10.1192/bjp. 183.3.233

Wells, G. L. (1978). Applied eyewitness-testimony research: System variables and estimator variables. Journal of Personality and Social Psychology, 36, 1546-1557. doi:10.1037/0022-3514.36.12.1546

Zhu, B., Chen, C. S., Loftus, E. F., Lin, C. D., He, Q. H., Chen, C. H., ... Dong, Q. (2010). Individual differences in false memory from misinformation: Cognitive factors. Memory, 18, 543-555. doi:10.1080/0965 8211.2010 .487051 